\title{
Report on "Methodologies for Investigating Microbial-Mineral Interactions: A Clay Minerals Society Short Course"
}

\author{
Patricia A. Maurice \\ University of Notre Dame
}

Geomicrobiology is a rapidly evolving discipline that has emerged over the last few decades at the intersection of Geology, Geochemistry, Microbiology, Microbial Ecology, and Environmental Engineering. Many fundamental geochemical reactions and processes cannot be understood without taking into consideration the complex role of microorganisms. Moreover, geological materials, most notably clays and clay minerals, are important sources of essential nutrients such as Fe and phosphate for microorganisms; provide surfaces for attachment and formation of biofilms; and adsorb natural organic matter, toxic organic and inorganic pollutants, and nutrient metals, hence affecting their distributions, mobilities, and bioavailabilities to microbial communities.

Studies of Microbial-Mineral interactions require the use and continued development of specialized methods that explicitly take into consideration the dynamic behaviors of microorganisms, along with the complex hydrobiogeochemical properties of the mineral-microbial-water interface. Perhaps most importantly, this emerging field calls for a new generation of scientists and engineers who are properly trained in their individual disciplines, and also in the complex approaches and methods of Geomicrobiology.

To this end, a workshop entitled, "Methods of Investigating Microbial-Mineral Interactions," was held at the Clay Minerals Society meeting at the Pacific Northwest National Laboratory in Richland, WA on June 19, 2004. The workshop was organized by Patricia A. Maurice (University of Notre Dame) and Lesley A. Warren (McMaster University, CA). Speakers included: Dr. P. Bennett, Dr. J. Fredrickson (PNNL), Dr. S. Lower (Ohio State University), Dr. P. Maurice, Dr. S. Myneni (Princeton University), Dr. E. Shock (Arizona State), Dr. M. Tien (Penn State), Dr. L. Warren, and Dr. J. Zachara (PNNL). There were approximately 75 attendees at the workshop, including more than 20 students. A workshop volume was published by the Clay Minerals Society [Methods for Study of Microbe-Mineral Interactions (2006), CMS Workshop Lectures, vol. 14(Patricia A. Maurice and Leslie A. Warren, eds.) ISBN 978-1-881208-15-0, 166 pp.] 